\title{
Consejos del Poder Ciudadano y gestión pública en Nicaragua
}

Roberto Stuart Almendárez (Coordinador de la Investigación)

Comentario de Manuel Ortega Hegg

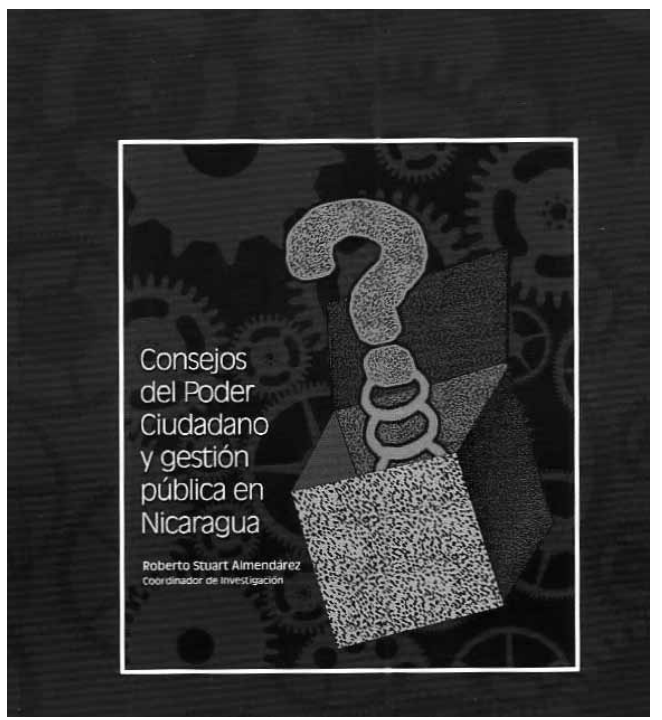

Este estudio, además de aportar al país, demuestra la importancia que tienen las ciencias sociales en el análisis de los fenómenos sociales. Uno se puede preguntar, ¿cuál es el aporte que hace este estudio al conocimiento que se tiene de los Consejos del Poder Ciudadano (CPC)? Se podría decir que muchas de las cosas que se dicen en esta investigación ya las sabíamos: que son una organización del Frente Sandinista, que dependen de la Presidencia de la República misma, que han venido sustituyendo al sistema de participación anterior, que tienden a ser excluyentes. Todas estas cosas ya las sabíamos. Sin embargo, lo importante de este estudio reside en proporcionar una fuerte base empírica al conocimiento que teníamos, verificando lo que ya sabíamos en la realidad. Ahora tenemos datos de la realidad empírica que nos muestran efectivamente cómo están funcionando, qué características tiene el poder de los CPC. Me parece, por lo tanto, que la primera bondad del estudio es que brinda datos empíricos con los que verifica los datos conocidos.

Pero también este estudio nos permite conocer que hay una lógica y una racionalidad muy clara detrás de los CPC. Muestra, por ejemplo, que los CPC no son comprensibles en sí mismos. Uno no llega a entender totalmente a los CPC si no entiende que detrás de ellos hay todo un proyecto completo, dentro del cual los CPC no son más que un componente. Ese proyecto tiene que ver con un fenómeno que está ocurriendo en toda América latina y se relaciona con el surgimiento de los llamados gobiernos de izquierda. Digo llamados gobiernos de izquierda porque ahora hay un debate en torno a quiénes son gobiernos de izquierda y quiénes no. En Nicaragua los términos no están claros, pero sí es claro en América Latina que hay izquierdas diversas. Algunos hablan de gobiernos de izquierda y otros de gobiernos progresistas. Sea lo que sea, esta izquierda que ha llegado al poder -al menos en ocho o diez países de América Latina- ha levantado como bandera en cada caso un proyecto de transformación de los países.

El contexto es que se ha agotado el modelo neoliberal anterior. Y al agotarse las propuestas políticas anteriores, estos nuevos gobiernos de izquierda en América Latina llegan con una 
nueva propuesta que tiene como eje la instauración de un modelo de mayor redistribución social. Sin embargo, lo primero que encuentran es que para poder hacer realidad ese modelo de mayor redistribución social y de mejorar la lucha contra la pobreza, etc., se requiere de más tiempo que los cuatro a cinco años que duran los períodos de gobierno. Se enfrentan así al problema de cómo hacer transformaciones sociales en condiciones de lucha electoral -que se establece cada cuatro o cinco años- cuando en cada lucha electoral se pone en juego el gobierno mismo. Cada vez que hay elecciones está en juego el poder institucional, un poder necesario para continuar las transformaciones.

¿Cómo hacer entonces para garantizar que los cambios, que son de largo plazo, se puedan hacer en los cortos plazos de los períodos de gobierno? Surge entonces el montaje de toda una estrategia que tiene como objetivo precisamente garantizar la continuidad en el poder para garantizar el proyecto político de largo plazo.

Como parte de esta estrategia, en toda América Latina todos los gobiernos de izquierda, salvo alguna excepción, han planteado al menos dos acciones: primero -en los casos donde no había posibilidad de reelección- la reforma de las Constituciones para permitir la reelección sucesiva de los gobiernos; y segundo, todos estos gobiernos -empezando por Venezuela, donde se inició el modelo- han venido organizando y ampliando una base social que se convierta en base electoral permanente. En el caso de Venezuela este proceso se inició con los llamados círculos bolivarianos, que ahora se han convertido en grupos comunitarios que tienen un tendido territorial que abarca todo el país. Chávez no tenía un partido político, por lo que él comenzó a articular su poder sobre la base del tendido territorial de estos movimientos comunitarios. Su objetivo era ampliar y transformar esta organización comunitaria en una enorme base electoral. No es casual que Chávez haya llegado al poder con menos del 45\% y que en la última elección haya sacado el $62 \%$ de los votos. El secreto es este tendido territorial a través del cual hay un derrame de recursos a través de diversos programas. Estas organizaciones comunitarias desempeñan funciones totalmente gubernamentales. Es decir, este tendido comunitario se convierte es un Estado paralelo. Chávez lo dijo en discurso muy claramente: "El Estado que yo encontré es un Estado que no permite gobernar. Es un Estado totalmente burocrático, acostumbrado al viejo estilo de gobernar, donde el burócrata se atrinchera. Yo necesito un Estado que me dé respuestas inmediatas". Y la respuesta fue el montaje de un Estado paralelo. Al menos al comienzo de su gobierno, las misiones de salud, por ejemplo, recibían más dinero para ejercer toda una serie de acciones en el territorio que lo que recibía el Ministerio de Salud formal. En educación ocurría algo parecido. Se montó así ese sistema paralelo que además se ha logrado convertir en base electoral y que ha dado sus frutos incrementando el número de votos para Chávez.

Esta estrategia está funcionando en Nicaragua y se encuentra detrás de la persistencia del Presidente Daniel Ortega en la reforma institucional que permita la reelección sucesiva e indefinida. Pero también en la importancia que el Presidente Ortega le ha otorgado a la organización de los CPC. Recordemos el conflicto por institucionalizar la organización de los CPC como organizaciones paragubernamentales que llegó al extremo de paralizar los poderes del Estado en el año 2007. Al final, el gobierno no logró su objetivo, pues la Corte Suprema de Justicia prohibió que estas organizaciones jugaran funciones gubernamentales 
y que recibieran recursos del Estado, aunque permitió su existencia; pero el conflicto fue tan grande que mantuvo paralizado a los poderes del Estado hasta que esa decisión salomónica logró convertir en sentencia los acuerdos que permitieron la continuidad institucional.

En aquellos momentos del conflicto entre la oposición y el Presidente Ortega por los CPC uno se preguntaba, ¿́por qué son tan importantes los CPC para el Presidente Daniel Ortega como para estar dispuesto a paralizar los poderes del Estado si no se aprobaban con las funciones y potestades propuestas? La respuesta era muy clara: porque los CPC representan el eje de la posibilidad de continuidad del proyecto político del Frente Sandinista de Daniel Ortega y Rosario Murillo. Aunque sea sólo de paso, es importante señalar que los CPC también representan un eje muy importante de la conversión del FSLN en un partido de masas, pero además significan una palanca fundamental en manos del gobierno y la cúpula del FSLN para presionar al resto del sistema político, empezando por los poderes del Estado. Esto puede percibirse claramente en este estudio de los CPC, donde se hace visible la lógica con la que éstos se organizan.

Esa estrategia implica también mantenerse en campaña política permanente para ir convirtiendo las acciones de gobierno y la derrama de recursos en votos. El clientelismo político es un resultado inevitable y casi natural de esta estrategia. Eso explica por qué en Nicaragua la campaña política del Presidente Ortega no terminó con los resultados electorales del año 2006, cuando ganó la Presidencia con un ajustadísimo 38\% de los votos y una oposición dividida. Hacia el futuro de una posible reelección, es necesario mantener a esa oposición dividida, pero también aumentar el caudal de votos. Y para ello hay que mantenerse en campaña política, aunque ello polarice al país, pues todos sabemos que una de las características de las campañas políticas es la polarización que provocan. Evidencias de esa campaña es el culto permanente al Presidente Ortega, los grandes rótulos en las calles y en las carreteras, la movilización constante de los partidarios en portátiles muy eficientes, los discursos y posiciones políticas del Presidente Ortega más bien partidarios que de estadista, pues no toman en cuenta que hay una sociedad plural y diversa y que no todo mundo piensa igual ni está afiliado a un partido único. Aquí no es necesario ser un observador acucioso para darse cuenta que el país se mantiene cada día más polarizado y con altos niveles de incertidumbre, producto en buena parte de esta estrategia electoral permanente. Tampoco resulta casual que la cabeza de los CPC esté en la Presidencia de la República, más concretamente en Rosario Murillo, esposa del Presidente Ortega, que es además jefa de campaña del FSLN. Y que además, los CPC en el territorio estén organizados de acuerdo a la ruta electoral del Consejo Supremo Electoral, según muestra el estudio que comentamos.

Por otro lado, a la par de la campaña electoral permanente, es posible observar cómo la estrategia contempla una serie de programas gubernamentales que funcionan bajo la lógica de crear fidelidades y lealtades políticas. El estudio que estoy comentando proporciona evidencias de cómo la contrapartida solicitada al beneficiario de los programas es su participación en las actividades del partido FSLN. El sistema funciona entonces como un sistema fundamentalmente clientelar, al igual que en Venezuela. Esto trae consecuencias negativas para el proceso que hemos venido trabajando durante todos estos años de construcción de ciudadanía, en donde la relación del ciudadano con el Estado se establece 
en términos de deberes y derechos y no en términos de recibir prebendas o 'favores' a cambio de lealtades políticas personales. Este modelo inevitablemente promueve un sistema clientelar por la sencilla razón de que es un sistema diseñado fundamentalmente para conseguir votos y el voto no se espera como resultado de procesos de largo plazo con la transformación de la conciencia del ciudadano. El voto se requiere de forma inmediata (al menos cada cinco años), como contra partida del bono productivo o del crédito, o del favor, o lo que sea. Se trata de un modelo que está montado sobre la base de lo que algunos politólogos llaman neopopulismo, es decir, de una relación directa del líder con las bases políticas que obvia la institucionalidad existente y que genera lealtades sobre la base de la concesión de "favores". Cabe indicar que este sistema necesita recursos para repartir y eso se ha resuelto en Nicaragua con la llamada "ayuda venezolana" que ha sido privatizada con estos fines por la familia gobernante.

Cabe recordar que la institucionalidad que está establecida en el país para la participación ciudadana no son los CPC. Los CPC están establecidos por un decreto ejecutivo, que es una legislación de rango inferior a la ley. La jerarquía de las leyes está constituida por la Constitución, que es la ley máxima del país, las leyes de rango constitucional, los códigos o leyes y después el decreto. La Ley de Participación Ciudadana es la que establece el sistema vigente de participación ciudadana, y es por jerarquía, una ley superior al decreto con que el Presidente Ortega ha constituido los CPC.

Por otro lado, aunque los CPC estén fundamentados en un decreto, lo que se está implementando no es lo establecido por el decreto, pues el estudio muestra cómo los CPC en la campaña electoral municipal del 2008 repartían recursos gubernamentales, como zinc, materiales de construcción, bonos productivos y otros, como parte de la campaña electoral. Esta es una evidencia de un fenómeno que también se ha observado en América Latina, y que se llama proceso de desinstitucionalización del Estado. Esta es resultado de un estilo de gobierno que establece relaciones directas de los gobernantes con la población, pasando por encima de las instituciones. América Latina, que tiene una experiencia bastante corta en institucionalidad y democracia salvo excepciones, no cabe duda que va a pagar un costo muy alto por este proceso de desinstitucionalización. Va a tomar años volver a crear la institucionalidad que en este momento se está erosionado. Y no se trata de una defensa a ultranza de las instituciones existentes. Las instituciones no pueden ser eternas y deben modificarse con los cambios de la sociedad. Sin embargo, esos cambios deben hacerse con los procedimientos y los trámites establecidos, so peligro de que los ciudadanos queden en manos de la discresionalidad y aún arbitrariedad de cada gobernante.

Como se señala en el estudio, la implementación de esta estrategia no solamente está desinstitucionalizando al país, sino que también están modificando la relación del gobierno central con los gobiernos locales, produciendo una recentralización del poder y una pérdida de autonomía de los gobiernos locales. Recordemos, por ejemplo, cómo todos los candidatos a alcaldes del Frente Sandinista tuvieron que firmar un documento en donde se comprometían a someterse a los CPC cuya cabeza es la esposa del Presidente, a gobernar de acuerdo a lo que los CPC establecieran, bajo la premisa que los CPC son el pueblo y es el pueblo el que manda. Por lo tanto, este modelo lleva a que los alcaldes -que son electos por toda la población y no sólo por los miembros de los CPC- tengan que atender las demandas 
de un sector de la población organizado por los CPC y no de la población en su conjunto. Además, crea un problema con la democracia representativa, es decir, entre los electos y la democracia directa establecida por la población. Se crea un conflicto que el sistema no logra resolver totalmente.

Por otro lado, destaco la referencia que hace el estudio a la sostenibilidad del modelo, sin el FSLN en el poder. Es algo que tiene que ver con el problema de la institucionalidad, que tiene que ver con el diseño del poder y que dejo a sus comentarios.

Sin embargo, no todo es negativo en el análisis de los CPC. Considero que el hecho de que un partido político con una alta organización a nivel nacional, como es el Frente Sandinista -por muy debilitado que pueda haber estado por los años de ser oposición- se meta a organizar a la población para a incidir en la gestión de gobierno, por débil y parcial que sea esa gestión, releva un aspecto positivo digno de destacarse. Hace que más gente esté preocupada por los asuntos locales, los asuntos de la población, que se metan más en la gestión municipal. Esto es positivo aunque sepamos que no en todos los casos esta participación está orientada a resolver los problemas locales, sino más bien a los asuntos que son orientados de arriba hacia abajo. Sin embargo, es un hecho que hay una especie de democratización de la organización ciudadana participando en los espacios de incidencia en el gobierno. También se amplía de alguna manera la sociedad civil a una sociedad civil más popular al organizar a la sociedad civil de los barrios para incidir en el gobierno. Ello aunque el modelo no tenga como una de sus preocupaciones la deliberación ciudadana, tan fundamental en una democracia.

No obstante, los CPC tienen grandes retos. El modelo tendría que abrirse evidentemente a la diversidad, al pluralismo, a la inclusión real de todos y todas. Tendría que abrirse a la tolerancia. El modelo, en su base, es bastante abierto, como señala el estudio. Pero en la medida que sube es un modelo que se va cerrando. Hemos estado haciendo estudios en la UCA en los últimos años sobre el tema de la tolerancia como uno de los valores democráticos. Una de las cosas que observan estos estudios es que cuando termina la guerra del noventa la intolerancia había crecido enormemente durante la guerra. Y ello es así porque la mayor intolerancia que puede tener un país es precisamente la guerra, cuando los asuntos se resuelven por las balas. Inmediatamente después del noventa, la tolerancia comienza a ganar espacios y empieza a caer la intolerancia en la medida en que las personas se van integrando a la vida cívica y se va produciendo la pacificación la sociedad. Después del año 2000 , todas las mediciones que tenemos en encuestas, tanto nosotros como otros científicos sociales, como por ejemplo la encuesta de Opinión Pública de América Latina (LAPOP), lo que muestran es que la intolerancia en el país esta creciendo nuevamente. Y esto es un fenómeno absolutamente negativo en el país. Obstaculiza nuestra capacidad de enfrentar juntos la crisis del país, por ejemplo. Es fundamental que sintamos que todos podemos darnos un espacio para colaborar y buscar de una u otra manera soluciones conjuntas. La tolerancia es un valor elemental de convivencia social en sociedades abiertas, plurales y diversas.

El sistema tiene que abrirse no solamente a la tolerancia sino también a la construcción de ciudadanía, uno de los elementos más afectados por esta estrategia, como ya señalé. 
Estamos retornando otra vez a un sistema clientelar. Para avanzar, el sistema CPC tiene que abrirse a la autonomía de las relaciones de la sociedad civil con el Estado. La única manera en que la sociedad civil puede controlar al Estado es siendo autónoma del propio Estado, no dependiendo del Estado ni del partido, porque de lo contario se termina siendo un instrumento del partido o del gobierno y defendiendo sus intereses y no los intereses de la propia sociedad civil.

Otro aspecto central es que este sistema requeriría abrirse a la deliberación. Debería ser un sistema en donde la ciudadanía pueda encontrar espacios de participación, en donde pueda discutir sus problemas, en donde pueda debatir soluciones. Un sistema así considerado, tendría como resultado una ciudadanía propositiva, una ciudadanía que no recibe orientaciones de arriba a abajo sino una ciudadanía que de abajo a arriba revisa los problemas, discute los problemas y propone soluciones. Me parece por lo tanto que estamos frente a una serie de retos.

Por otro lado, este estudio también muestra que estamos en un momento de polarización y que se hace necesaria una distensión en el sistema participativo, en el sistema político mismo. Tenemos la convicción de que todos estos procesos solamente van a sacar al país de la situación de crisis y de la pobreza que lo agobia en la medida en que consigamos esquemas de participación y de convergencia que sean capaces de incluir a todos.

Una lección fundamental de nuestra historia es que el conflicto se vuelve inevitable en la medida en que hay personas que no se sienten incluidas en el sistema social y político. Quien no se siente incluido inmediatamente empieza a deslegitimizar al sistema que le excluye. En la medida en que encontremos la posibilidad de crear espacios influyentes, de aceptar la diversidad, de aceptar el pluralismo, de aceptar que todos tenemos derechos y que podemos convivir juntos independientemente de nuestras posiciones, en esa misma medida vamos a poder salir adelante.

Termino agradeciendo nuevamente a los autores del estudio por sus hallazgos tan útiles al país y por la oportunidad de estos comentarios, y recomendando su lectura detenida. Muchas gracias. 